February 2004 - NREL/CP-560-35569

\title{
Interconnection Testing of Distributed Resources
}

\section{Preprint}

\section{B. Kroposki, T. Basso, and R. DeBlasio}

To be presented at the 2004 Power Engineering Society General Meeting Denver, Colorado June 7, 2004

This work has been submitted to the IEEE for possible publication. Copyright may be transferred without notice, after which this version may no longer be accessible.

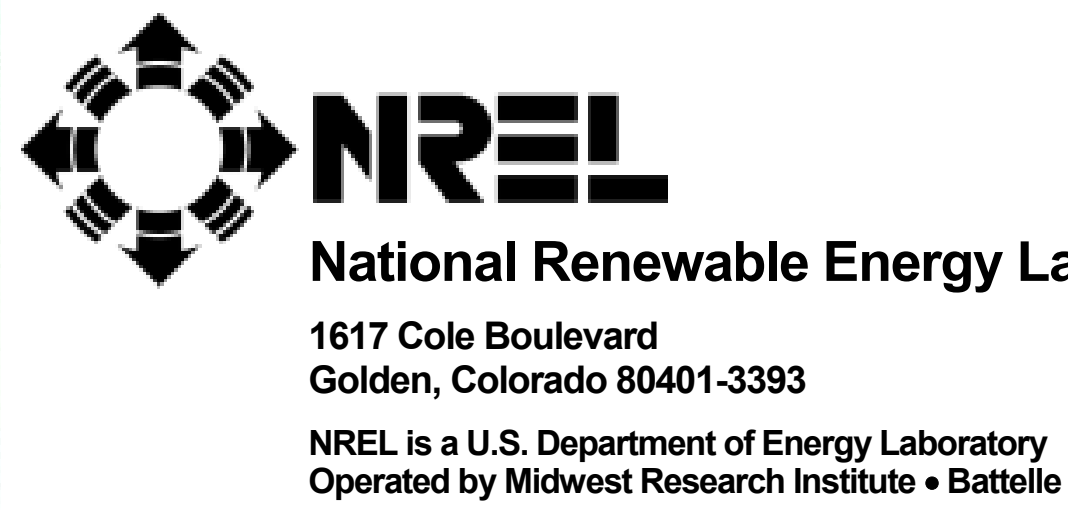




\section{NOTICE}

The submitted manuscript has been offered by an employee of the Midwest Research Institute (MRI), a contractor of the US Government under Contract No. DE-AC36-99G010337. Accordingly, the US Government and MRI retain a nonexclusive royalty-free license to publish or reproduce the published form of this contribution, or allow others to do so, for US Government purposes.

This report was prepared as an account of work sponsored by an agency of the United States government. Neither the United States government nor any agency thereof, nor any of their employees, makes any warranty, express or implied, or assumes any legal liability or responsibility for the accuracy, completeness, or usefulness of any information, apparatus, product, or process disclosed, or represents that its use would not infringe privately owned rights. Reference herein to any specific commercial product, process, or service by trade name, trademark, manufacturer, or otherwise does not necessarily constitute or imply its endorsement, recommendation, or favoring by the United States government or any agency thereof. The views and opinions of authors expressed herein do not necessarily state or reflect those of the United States government or any agency thereof.

Available electronically at http://www.osti.gov/bridge

Available for a processing fee to U.S. Department of Energy and its contractors, in paper, from:

U.S. Department of Energy

Office of Scientific and Technical Information

P.O. Box 62

Oak Ridge, TN 37831-0062

phone: 865.576 .8401

fax: 865.576.5728

email: reports@adonis.osti.gov

Available for sale to the public, in paper, from:

U.S. Department of Commerce

National Technical Information Service

5285 Port Royal Road

Springfield, VA 22161

phone: 800.553 .6847

fax:703.605.6900

email: orders@ntis.fedworld.gov

online ordering: http://www.ntis.gov/ordering.htm 


\title{
Interconnection Testing of Distributed Resources
}

\author{
Benjamin Kroposki, Senior Member, IEEE, Thomas Basso, Member, IEEE, \\ and Richard DeBlasio, Senior Member, IEEE
}

\begin{abstract}
With the publication of IEEE 1547-2003 ${ }^{\mathrm{TM}}$ Standard for Interconnecting Distributed Resources With Electric Power Systems, the electric power industry has a need to develop tests and procedures to verify that interconnection equipment meets 1547 technical requirements. A new standard, IEEE P1547.1 ${ }^{\mathrm{TM}}$, is being written to give detailed tests and procedures for confirming that equipment meets the interconnection requirements. The National Renewable Energy Laboratory has been validating test procedures being developed as part of IEEE P1547.1. As work progresses on the validation of those procedures, information and test reports are passed on to the working group of IEEE P1547.1 for future revisions.
\end{abstract}

Index Terms-Dispersed storage and generation, power distribution, power system testing, power system transients, synchronous generators, test equipment, test facilities.

\section{INTRODUCTION}

$\mathrm{R}$ ECENT advancements in distributed resources (DR) have allowed for their increased use and integration into the electric power system (EPS). DR are generation and storage located at or near the point of use. Examples include photovoltaics, wind turbines, microturbines, fuel cells, and internal combustion engines.

When interconnected with the electric power system at or near load centers, these technologies can provide increased efficiency, availability, and reliability; better power quality; and a variety of economic and power system benefits. These benefits have created new interest in distributed power applications, which has led industry to call for standards that address the interconnection of DR.

In response, the Institute of Electrical and Electronics Engineers (IEEE) approved a standard to help utilities use electricity from dispersed sources: IEEE 1547-2003 Standard for Interconnecting Distributed Resources With Electric Power Systems [1]. This standard established the technical requirements for interconnecting DR with EPSs.

The 1547 standard focuses on the technical specifications for, and the testing of, the interconnection itself. It provides requirements relevant to the performance, operation, testing, safety, and maintenance of the interconnection. It covers general requirements, response to abnormal conditions, power

This work was supported in part by the U.S. Department of Energy under Contract No. DE-AC36-99-GO10337.

B. Kroposki is with the National Renewable Energy Laboratory, Golden, CO 80401 USA (e-mail: ben_Kroposki@nrel.gov).

T. Basso is with the National Renewable Energy Laboratory, Golden, CO 80401 USA (e-mail: thomas_basso@nrel.gov).

R. DeBlasio is with the National Renewable Energy Laboratory, Golden, CO 80401 USA (e-mail: deblasid@tcplink.nrel.gov). quality, islanding, and test specifications and requirements for design, production, installation evaluation, commissioning, and periodic tests. These requirements are universally needed for the interconnection of DR-including synchronous generators, induction generators, and power inverters/converters - and will be sufficient for most installations. They are applicable to all DR technologies with aggregate capacity of $10 \mathrm{MVA}$ or less at the point of common coupling that are interconnected with EPSs at typical primary or secondary distribution voltages. The installation of DR on radial primary and secondary distribution systems is the emphasis of the 1547 standard, but installation on primary and secondary network distribution systems is also considered.

IEEE Standards Coordinating Committee (SCC) 21 [2] is also developing IEEE P1547.1 Draft Standard Conformance Test Procedures for Equipment Interconnecting Distributed Resources With Electric Power Systems" [3], an accompanying standard that will address conformance tests and procedures for verifying interconnection equipment.

Standards are created through collaboration and agreement among experts from all related fields, including utilities, equipment manufacturers, and government laboratories. Uniform interconnection requirements should help all parties realize the benefits of DR while saving time and money.

The National Renewable Energy Laboratory (NREL) has been instrumental in the development of standard interconnection requirements for DR and the validation of test procedures for the IEEE 1547 and P1547.1 standards [4].

\section{INTERCONNECTION TESTS}

Historically, utility EPSs were not designed to accommodate active generation and storage at the distribution level. In addition, the multitude of utility companies employed numerous EPS architectures based on differing designs and choices of equipment. As a result, there are major obstacles to an orderly transition to using DR with the grid.

IEEE 1547 lists technical requirements for interconnection. IEEE P1547.1 specifies the type, production, and commissioning tests necessary to demonstrate that the interconnection equipment of DR conform to IEEE 1547.

Standardized test procedures are necessary to establish and verify compliance with those requirements. These test procedures must provide both repeatable results, independent of test location, and flexibility to accommodate a variety of DR technologies. 
IEEE P1547.1 details specific procedures for:

\section{Type (Design) Tests}

- Response to abnormal voltage conditions

- Response to abnormal frequency conditions

- Synchronization

- Interconnection integrity (includes protection from electromagnetic interference, surge withstand, and ability of the paralleling device to withstand out-ofphase voltage)

- DC injection

- Unintentional islanding

- Reverse power

- Cease to energize and loss of phase

- Reconnect following abnormal conditions

- Harmonics

- Flicker

- Temperature stability

\section{Production Tests}

- Response to abnormal voltage conditions

- Response to abnormal frequency conditions

- Synchronization

\section{Commissioning Tests}

The working group developing the standard is using the body of testing knowledge as much as possible. For example, the surge withstand tests are based on currently accepted industry practice IEEE C62.41 [5] and IEEE C62.45 [6]. However, during testing standard development, it was recognized that some procedures for confirming interconnection requirements did not exist.

These new test procedures are being developed as part of IEEE P1547.1 and validated on a variety of DR types at NREL's Distributed Energy Resources Test Facility [7] in Colorado. As work on the validation of procedures progresses, information and test reports are passed on to the working group of IEEE P1547.1.

\section{TEST FACILITY AND EQUIPMENT}

NREL's Distributed Energy Resources Test Facility provided the platform used to validate some of the IEEE P1547.1 tests. It includes a DR interconnection monitoring system and test switchboard that facilitates connecting a utility source, a DR source, and a local load bus. For most of the testing, the DR source (inverter- or synchronous generatorbased), interconnection equipment, a $200-\mathrm{kW}$ grid simulator, a $100-\mathrm{kW}$ real load bank, and a $200-\mathrm{kW}$ real and reactive (inductive and capacitive) load bank were incorporated into the switchboard.

\section{A. Data Acquisition System}

Because many of the parameters tested involve subcycle transient times, a relatively high-speed data acquisition system was necessary. The data acquisition system is capable of sampling rates up to 5 million samples per second $(\mathrm{S} / \mathrm{s})$. For this testing, however, sampling rates ranged from 10,000 to $250,000 \mathrm{~S} / \mathrm{s}$. The voltage and current measurements are accurate to $\pm 0.2 \%$ of the reading values, with a time scale accuracy of $\pm 0.05 \%$.

\section{B. Utility Grid Simulator}

An array of four grid simulators was used to perform controlled simulations of abnormal grid conditions. Four units were paralleled to provide a combined capacity of 250 $\mathrm{kVA}(200 \mathrm{~kW})$ at 120/208 V. All four units are controlled via a master-slave arrangement that allows the units to operate simultaneously. Each unit is rated at $62.5 \mathrm{kVA}$ and is capable of delivering power at frequencies from $50 \mathrm{~Hz}$ to $400 \mathrm{~Hz}$.

The grid simulator is a double-conversion power source. Commercial input power is rectified and then converted to precision AC power through high-frequency, pulse-width modulation. This design allows fully programmable control of individual phase voltage, current, and frequency.

The grid simulator is capable of fast response times, reacting to a $100 \%$ step load change in less than $300 \mu \mathrm{s}$.

The output of the four-unit array is connected to a 125:277$\mathrm{V}$ wye autotransformer to provide a three-phase, $480-\mathrm{V}_{\mathrm{L}-\mathrm{L}}$ output. Output regulation and total harmonic distortion are less than $1 \%$ for normal $60-\mathrm{Hz}$ operations.

\section{Load Bank}

The load bank used for these tests is a customized version modified to provide up to $165 \mathrm{~kW}$ resistive and $404 \mathrm{kVAR}$ inductive and capacitive loads in step sizes as small as $125 \mathrm{~W}$ and 312.5 var. A graphical user interface controls the unit through serial ports.

\section{Synchronous Generators}

A Cummins/Onan 125-kW model DGEA diesel generator was used to test ASCO and GE interconnection equipment.

\section{E. ASCO 7000 Series Soft-Load Transfer Switch}

The ASCO 7000 Soft-Load Transfer Switch (SLTS) is designed to provide a safe and controllable interconnection of the EPS, a synchronous generator, and load. This interconnection switch has traditionally been used for emergency power applications but is increasingly being used for grid-parallel operation. Avoiding significant voltage or frequency transients, the ASCO SLTS can seamlessly transfer or share load between the generator and utility bus.

The setup employed for the ASCO SLTS is typical of devices used to interconnect DR equipment with utility buses and therefore provides a general platform for the development and verification of standard test procedures. Both the utility and generator breakers used in the installation have shunt trip, and the output of the auxiliary contact of the utility shunt trip breaker is used as a trigger for capturing test data.

The ASCO SLTS has a variety of protective relay functions, and many have adjustable tolerance ranges through the ASCO controls [8], [9]. 
These include:

- Synchronization

- Overvoltage and undervoltage

- Overfrequency and underfrequency

- Reverse power and underpower

- Negative sequence voltage and current

- Directional overcurrent

- Loss of excitation

- A proprietary algorithm for detecting and disconnecting a generator during an island condition.

\section{F. GE Universal Interconnect Prototype}

The GE Universal Interconnect (UI) is a prototype interconnection system based on the GE G60 Universal Generator protection relay from GE Multilin and a GE Zenith transfer switch. The GE UI is designed to allow the interconnection of any distributed generator with the EPS and provide a local load connection. It operates in a manner similar to the ASCO STLS and provides seamless transfer between the utility and generator to provide power to the load.

\section{TEST RESUltS}

The testing reported in this section focuses on three requirements of IEEE 1547: response to abnormal voltage conditions, response to abnormal frequency conditions, and unintentional islanding. Tables I and II give the required clearing times for the interconnection system to respond to abnormal voltage and frequency conditions.

TABLE I

RESPONSE TO ABNORMAL VOLTAGE

\begin{tabular}{|l|l|}
\hline \multicolumn{1}{|c|}{$\begin{array}{c}\text { Voltage Range } \\
\text { (Based on 480 V) }\end{array}$} & Clearing Time (s) \\
\hline $\mathrm{V}<240$ & 0.16 \\
\hline $240 \leq \mathrm{V}<422.4$ & 2 \\
\hline $528<\mathrm{V}<576$ & 1 \\
\hline $\mathrm{V} \geq 576$ & 0.16 \\
\hline
\end{tabular}

TABLE II

RESPONSE TO ABNORMAL FREQUENCY

\begin{tabular}{|c|l|l|}
\hline DR & \multicolumn{1}{|c|}{ Frequency Range $(\mathrm{Hz})$} & Clearing Time $(\mathrm{s})$ \\
\hline \multirow{2}{*}{$\leq 30 \mathrm{~kW}$} & $>60.5$ & 0.16 \\
\cline { 2 - 3 } & $<59.3$ & 0.16 \\
\hline \multirow{3}{*}{$>30 \mathrm{~kW}$} & $>60.5$ & 0.16 \\
\cline { 2 - 3 } & $\begin{array}{l}<\{59.8-57.0\} \text { (adjustable } \\
\text { setpoint) }\end{array}$ & Adjustable $0.16-300$ \\
\cline { 2 - 3 } & $<57.0$ & 0.16 \\
\hline
\end{tabular}

The grid simulators were used to set test conditions. Only the parameter under test (PUT) was allowed to vary for each test. After establishing a certain test condition (undervoltage, overfrequency, unintentional island, etc.), the interconnection system must disconnect the DR from the utility system in less than the time required by IEEE 1547.
Adhering to IEEE P1547.1, both a magnitude and a time test were performed for the voltage and frequency response. The function of the magnitude test was to determine the actual trip point. This was accomplished by varying the PUT in tiny increments gradually approaching the trip set point. The slow approach accounts for any time delays and ensures that the bus conditions at the time of the trip are virtually identical to the actual trip magnitudes. Ramp functions from IEEE P1547.1 were programmed into and executed by the grid simulator.

After the trip magnitude was found, the time tests were used to determine the time until the device tripped when the trip conditions, as determined in the magnitude test, were established. The goal is to step from below to above (ordinarily at least 10\% above) the trip magnitude fast enough to know when the parameter jumps out of bounds and avoid introducing significant delays into the trip time. Testing of each parameter is conducted a minimum of five times to acquire a statistically significant sample.

For unintentional islanding, the requirement is that the DR interconnection system detect the island and cease to energize the Area EPS within $2 \mathrm{~s}$ of the formation of an island [1]. Islanding is when a distributed generator continues to supply power to a portion of the EPS when that portion of the grid is otherwise de-energized. Power utilities and regulatory requirements demand the prevention of unintentional islands to ensure the safety of utility personnel and the integrity of the power system. Ideally, the event that caused the local section of the grid to shut down should also trip the DR protective function, or the sudden increase in load from the loss of grid power should disrupt system conditions enough to trip the DR.

The IEEE 1547.1 unintentional islanding test is designed to simulate the worst-case scenario of matching the DR output to the load, adding capacitive and inductive load for a quality factor (Q) of 1.8, and dropping out the utility power without disturbing other system parameters. Previous islanding testing used $\mathrm{Q}=2.5$ [10]; IEEE 1547.1 standards now use $\mathrm{Q}=1.8$. $\mathrm{Q}=2.5$ corresponds to a load power factor $(\mathrm{PF})$ of 0.37 , and $\mathrm{Q}=1.8$ corresponds to a load power factor of 0.55 . $\mathrm{Q}=2.5$ was selected as the most difficult operating condition that an inverter anti-islanding algorithm would typically see. Further work has shown that utility circuits typically operate above $0.75 \mathrm{PF}$ in steady-state conditions; therefore, $\mathrm{Q}=1.8(\mathrm{PF}=$ 0.55 ) is below the load power factor that the DR would be expected to operate. Although it is unlikely in the field, successful worst-case testing demonstrates that the device can identify islands and quickly disconnect in most situations.

The testing procedure for unintentional islanding was similar to that for abnormal voltage and frequency. Initially, with the DR disconnected, the grid simulator would supply a local load $10 \mathrm{~kW}$ or $20 \mathrm{~kW}$ greater than the desired DR to avoid backfeeding the grid simulators when ramping up the output power of the DR. The DR was then paralleled and supplied most of the local load; the simulated utility still contributed 10-20 kW. Next, matched inductive and capacitive loads were added to achieve a quality factor of about 1.8. The capacitive load was then increased to reach the 
desired power factor (accounting for transformer and other system inductances), and the resistive load setting was slowly reduced to match the DR output with the load and eliminate current from the utility. Finally, the utility breaker was tripped to create the island, and the disconnect time was recorded.

The following sections describe selected results from the testing of the ASCO SLTS and GE UI. Complete details of the testing can be found in the final test reports [11], [12].

\section{A. ASCO SLTS}

The ASCO SLTS was tested for response to over and underfrequency, over and undervoltage, and unintentional islanding. The testing described in this paper builds on testing conducted previously at a field site [13]. The ASCO unit meets IEEE 1547 interconnection requirements by monitoring power conditions and sending a trip signal to the utility breaker after detecting any value outside of preset ranges.

Under the frequency test conditions, the ASCO unit controlled the diesel frequency to maintain a set export power level. By maintaining the grid simulator rate of frequency change below the time response of the diesel governor, the export power level could be held constant while bus frequency was decreased or increased. Table III shows the results from the magnitude portion of the overfrequency test, and Table IV shows the results from the time portion of the overfrequency test. The testing shows that the ASCO STLS disconnects from the abnormal frequency condition in the required time.

The general conditions established for the voltage tests were identical to those for frequency testing. Under the voltage test conditions, the ASCO controlled the genset excitation to maintain power factor. By maintaining the grid simulator rate of voltage change below the time response of the diesel exciter, power factor could be held constant while bus voltage was decreased or increased.

For the voltage testing, the most consistent results were with a non-unity power factor setting for the diesel generator. A power factor of 0.9 was used for these tests. This also provided a reactive load sink to limit generator reverse vars.

TABLE III

RESPONSE TO OVERFREQUENCY MAGNITUDE

\begin{tabular}{|l|l|}
\hline \multicolumn{1}{|c|}{ Test Run } & \multicolumn{1}{|c|}{ Frequency $(\mathrm{Hz})$} \\
\hline 1 & 60.458 \\
\hline 2 & 60.604 \\
\hline 3 & 60.461 \\
\hline 4 & 60.534 \\
\hline 5 & 60.531 \\
\hline Average & $\mathbf{6 0 . 5 1 8}$ \\
\hline Setting & $\mathbf{6 0 . 5}$ \\
\hline
\end{tabular}

TABLE IV

RESPONSE TO OVERFREQUENCY TIME

\begin{tabular}{|l|l|}
\hline \multicolumn{1}{|c|}{ Test Run } & \multicolumn{1}{|c|}{ Clearing Time (ms) } \\
\hline 1 & 47 \\
\hline 2 & 58 \\
\hline 3 & 40 \\
\hline 4 & 40 \\
\hline 5 & 39 \\
\hline Average & $\mathbf{4 5}$ \\
\hline Required & $\mathbf{1 6 0}$ \\
\hline
\end{tabular}

One of the issues of conducting the testing on an actual DR instead of testing via secondary injection methods is the operation of and pre-designed voltage regulator present on generator sets. The narrow range of the diesel voltage regulator would not allow testing at the voltage levels required by the IEEE 1547 and draft P1547.1 standards. IEEE 1547 has no disconnect or testing requirements for voltages ranging between $89 \%$ and $109 \%$ of normal. The voltage levels closest to nominal values that IEEE 1547 requires be tested are $88 \%$ of the nominal $480 \mathrm{~V}(422.4 \mathrm{~V})$ for undervoltage and $110 \%$ $(528 \mathrm{~V})$ for overvoltage. These levels are for the slow response testing; the fast response goes to less than $50 \%$ or greater than $120 \%$, but even the slow response minimum values were unattainable with the voltage regulator configuration. Voltage regulator settings prohibited the diesel generator from operating outside a range of only about $\pm 6 \%$ of nominal voltage $(450 \mathrm{~V}$ and $505 \mathrm{~V})$. To work around this restriction, set points within the range of the diesel were tested. This was done by manually relaxing the voltage set points programmed into the ASCO controller to only $\pm 25-30$ $\mathrm{V}$ around the nominal $480 \mathrm{~V}$. Testing over the full voltage range might have been possible after adjusting the diesel voltage regulator settings but could damage the generator.

Table $\mathrm{V}$ shows the results of the magnitude portion of the overvoltage test, and Table VI shows the results of the time portion of the overvoltage test. The testing shows that the ASCO STLS disconnects from the abnormal voltage condition in the required time.

TABLE V

ReSPONSE to OVERVOLtage Magnitude

\begin{tabular}{|l|l|}
\hline Test Run & Voltage $(\mathrm{V})$ \\
\hline 1 & 504.300 \\
\hline 2 & 502.500 \\
\hline 3 & 504.700 \\
\hline 4 & 504.600 \\
\hline 5 & 504.150 \\
\hline Average & $\mathbf{5 0 4 . 0 5 0}$ \\
\hline Setting & $\mathbf{5 0 4 . 0}$ \\
\hline
\end{tabular}

TABLE VI

RESPONSE TO OVERVOLTAGE TIME

\begin{tabular}{|l|l|}
\hline Test Run & Clearing Time (s) \\
\hline 1 & 0.436 \\
\hline 2 & 0.428 \\
\hline 3 & 0.378 \\
\hline 4 & 0.396 \\
\hline 5 & 0.468 \\
\hline Average & $\mathbf{0 . 4 2 1}$ \\
\hline Required & $\mathbf{1 . 0}$ \\
\hline
\end{tabular}

Unintentional islanding tests were conducted per the IEEE P1547.1 procedure. Placement of the load, whether entirely at the utility load or the local load, did not significantly influence the ASCO detection times, which averaged 17.12 or $17.14 \mathrm{~s}$ without the anti-islanding function operational. Therefore, all the later tests used only the local load to better simulate a generator interconnected with the grid but completely supplying only a local load. When the grid becomes deenergized, local system conditions do not immediately change, 
but the ASCO unit must still recognize the island and disconnect the generator within $2 \mathrm{~s}$. To further challenge the ASCO unit, inductive and capacitive elements were added to the local load to create a 1.8 load quality factor to help maintain local power characteristics after the loss of the utility.

Tests were conducted to investigate the effects of the diesel power factor setting, the generator load level, and the antiislanding deadband setting on the ASCO trip time. Loads at $25 \%(30 \mathrm{~kW}), 50 \%(63 \mathrm{~kW})$, and near $100 \%(100 \mathrm{~kW})$ were tested at unity load power factor with matching inductive and capacitive loads to create a 1.8 quality factor. Testing was conducted with the diesel power factor setting at unity, 0.9 lagging, and in some cases, 0.95 lagging. The deadband setting of the anti-islanding function is an adjustable sensitivity range. The active anti-islanding scheme attempts to disrupt the grid, and with no energized grid to maintain voltage and frequency, the ASCO can force values beyond the set deadband cushion before disconnecting the generator. Deadband settings of $0.1,0.05$, and 0.03 were used in tests.

Fig.1 shows that with the anti-islanding algorithm turned off, the ASCO unit could not meet the 2-s unintentional islanding requirement. With the anti-islanding algorithm turned on and a deadband setting of at least 0.05 , the unit could meet the 2-s trip requirement.

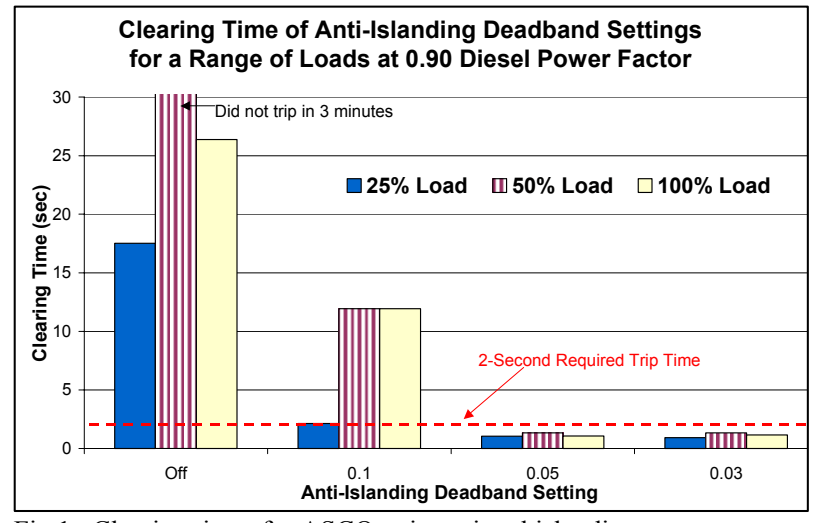

Fig 1. Clearing times for ASCO unintentional islanding tests

\section{B. GE Universal Interconnect}

Because the GE UI is based on a well-tested commercial relay, testing focused on the advanced modifications used to meet the unintentional islanding requirements of IEEE 1547. The GE strategy was to use a passive anti-islanding algorithm based on rate of change of frequency in addition to over/undervoltage and frequency limits to detect the unintentional island condition and disconnect within $2 \mathrm{~s}$.

The objective of the first set of tests was to find the nondetection zone for the anti-islanding function. By incrementally increasing or decreasing the mismatch in power between the generator and the load, the boundary at which the UI can detect an island condition can be found for any given power base load. The non-detection zone testing identifies the minimum power supplied by the utility that causes the UI to trip when the utility is removed. Within that power limit, the load matches the DR too closely, and the generator can run islanded indefinitely without the anti-islanding protection responding. This level gives an indication of how well the anti-islanding software operates and can be used as a performance index to compare anti-islanding techniques. The UI was tested at a variety of base loads but always with a consistent quality factor, taken as the ratio of the reactive load to the real load, of 1.8 .

After the active power mismatch testing, the UI was also tested with reactive power mismatch. The UI was never able to detect islanding with reactive power mismatch. The reason is that the diesel generator can quickly respond to the reactive power change, thus maintaining its terminal voltage. Theoretically, if the generator is controlled as a constant $\mathrm{P}$ and $\mathrm{Q}$ source, the active power mismatch will drive the frequency change, as the results above show. The reactive power mismatch, however, should cause voltage change, thus tripping under/overvoltage protection. However, it was not observed in the testing with this particular diesel generator, which apparently is not controlled as a constant reactive power source (or with a constant power factor). In these tests, the generator reactive output (DG Q) jumps up following the grid disconnection to compensate for the reactive power mismatch. As a result, the output voltage still remains within the normal range. If this is the typical or desired behavior of diesel generators used as DR, then anti-islanding protection based on voltage detection for this type of machine DR appears unfeasible. Other schemes that detect reactive power mismatch need to be developed in the future, though active power mismatch will be more common in practice.

In all test cases using only the passive anti-islanding detection scheme, even with the parameters tightened, the UI could not detect the island under exactly matched power conditions. To meet IEEE 1547 requirements, a reverse or minimum power trip setting would have to be used. Also, care must be taken when increasing the sensitivity of the antiislanding parameters because better protection can come at the potential price of increased nuisance tripping from unavoidable grid disturbances.

\section{SUMMARY}

This paper outlines some of the specific interconnection tests being validated for inclusion in IEEE 1547.1. The results of the testing have been passed on to the IEEE P1547.1 working group and help manufacturers of interconnection systems design equipment to meet the requirements.

The results of the validation studies include:

- Generic monitoring, measurement, and testing strategies could be useful in P1547.1. The file size, sampling rate, and correct sampling window were significant factors of testing that could be mentioned in P1547.1. The document should dictate universally prescriptive values and equipment-specific procedures. Advice and warnings of issues to be aware of to aid smooth and accurate testing should also be included. 
- Some values from the current P1547.1 draft standard were incompatible with the testing setup and will need modification. This information has been passed on to members of the IEEE P1547.1 working group for revision in future drafts.

- Care must be taken to test each parameter individually without other protective functions operating.

\section{ACKNOWLEDGMENTS}

The authors gratefully acknowledge the contributions of C. Pink and S. Engelbretson from the Colorado School of Mines for their assistance conducting tests. The authors also thank J. Daley, R. Siciliano, and D. Hinton from ASCO Power Technologies and Z. Ye and D. Finney from GE for their contributions with conducting tests and providing equipment.

\section{REFERENCES}

[1] IEEE Standard for Distributed Resources Interconnected With Electric Power Systems, IEEE Standard 1547-2003, July 2003.

[2] http://grouper.ieee.org/groups/scc21

[3] Draft Standard for Conformance Test Procedures for Interconnecting Distributed Resources with Electric Power Systems, IEEE P1547.1, November 2003.

[4] T.S. Basso and R. DeBlasio, "IEEE P1547 series of standards for interconnection: preprint," National Renewable Energy Laboratory, Golden, CO, NREL/CP-560-34003, May 2003. Available: http://www.nrel.gov/docs/fy03osti/34003.pdf.

[5] IEEE Recommended Practice on Characterization of Surges in Low Voltage (1000 V and Less) AC Power Circuits, IEEE Standard C62.41.22002.

[6] IEEE Recommended Practice on Surge Testing for Equipment Connected to Low-Voltage (1000 V and Less) AC Power Circuits, IEEE Standard C62.45-1992 (R2002).

[7] "NREL Distributed Energy Resources Test Facility: Advancing distributed power technology" fact sheet, National Renewable Energy Laboratory, Golden, CO, NREL/FS-560-35044, October 2003. Available: http://www.nrel.gov/docs/fy04osti/35044.pdf.

[8] J.M. Daley and R.L. Siciliano, "Application of emergency and standby generation for distributed generation: Part 1," presented at the Industrial and Commercial Power Systems Technical Conference 2002, pp. 138150 .

[9] J.M. Daley and R.L. Siciliano, "Application of emergency and standby generation for distributed generation: Part 2," presented at the Industrial and Commercial Power Systems Technical Conference 2002, pp. 151157.

[10] IEEE Recommended Practice for Utility Interface of Photovoltaic (PV) Systems, IEEE Standard 929-2000.

[11] B. Kroposki, S. Englebretson, C. Pink, J. Daley, R. Siciliano, and D. Hinton, "Validation of IEEE P1547.1 Interconnection Test Procedures: ASCO 7000 Soft Load Transfer System," National Renewable Energy Laboratory, Golden, CO, NREL/TP-560-34870, September 2003. Available: http://www.nrel.gov/docs/fy04osti/34870.pdf.

[12] Z. Ye, D. Finney, R. Zhou, M Dame, B. Premerlani, B. Kroposki, and S. Englebretson, "Testing of GE Universal Interconnection Device," National Renewable Energy Laboratory, Golden, CO, NREL/TP-560334676, August 2003. Available: http://www.nrel.gov/docs/fy03osti/34676.pdf

[13] B. Kroposki, R. DeBlasio, J. Galdo, "Distributed Power Program DER pilot test at the Nevada Test Site," National Renewable Energy Laboratory, Golden, CO, NREL/TP-560-32063, May 2002. Available: http://www.nrel.gov/docs/fy02osti/32063.pdf

\section{BIOGRAPHIES}

Benjamin Kroposki (S'90, M'93, SM'00) is a senior engineer at NREL and leader of the Distributed Power Systems Integration Team. His expertise is in the design and testing of distributed power systems, and he has produced more than 30 publications in this area. Kroposki also participates in the development of distributed power standards and codes for IEEE, the International Electrotechnical Commission (IEC), and the National Electrical Code. He serves as secretary for IEEE P1547.1. Mr. Kroposki received his bachelor's and master's degrees in electrical engineering from Virginia Tech and is a registered professional engineer.

Thomas Basso ( $\left.\mathrm{M}^{\prime} 80\right)$ is a senior scientist working at NREL under the NREL Distribution and Interconnection R\&D area of the NREL Distributed Energy and Electricity Reliability Program. Prior at NREL, he conducted outdoor accelerated weathering of photovoltaic (PV) modules and was NREL project leader for PV Management under the NREL/Department of Energy PV Advanced R\&D Project. Before coming to NREL, he was a design engineer with a consulting engineering firm and worked for a manufacturer of air-cooled heat exchangers for the petrochecmical, refinery, and utility industries. He was also a standards engineer for the American Society of Mechanical Engineers and an instructor in the Mechanical Engineering Department of Northeastern University. He serves as secretary for IEEE SCC21, P1547, P1547.2, and P1547.3 and is a member of the IEC Joint Coordination Group for Decentralized Rural Electrification Systems, IEC TC8, the American Society of Mechanical Engineers, and the American Solar Energy Society.

Richard DeBlasio (M'65, SM'83) is technology manager of the NREL/Department of Energy Distributed Energy and Electricity Reliability Program, which includes Distribution and Interconnection R\&D at NREL. Before joining NREL in 1978, he was with the U.S. Atomic Energy Commission in Washington, D.C. (1974-1978), and Underwriters Laboratories (1972-1974). He was also a member of the technical staff at Stanford University (1965-1972). He is an electrical engineer; a senior member of IEEE; an IEEE SA Standards Board member; chair of IEEE SCC 21 on Fuel Cells, Photovoltaics, Distributed Power, and Energy Storage; and chair of the international standards committees IEC TC82 and Joint Committee on Decentralized Rural Electrification Systems. 


\section{REPORT DOCUMENTATION PAGE}

Form Approved

OMB NO. 0704-0188

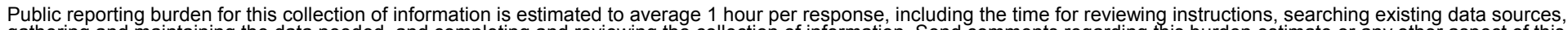

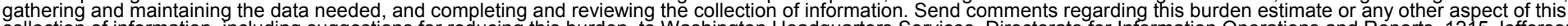

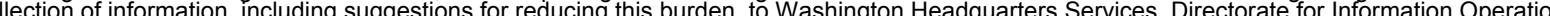

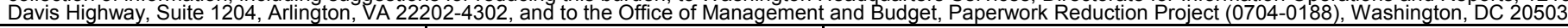
1. AGENCY USE ONLY (Leave blank)
2. REPORT DATE
February 2004
3. REPORT TYPE AND DATES COVERED
Conference Paper Preprint

4. TITLE AND SUBTITLE

Interconnection Testing of Distributed Resources: Preprint

5. FUNDING NUMBERS

6. $\mathrm{AUTHOR}(\mathrm{S})$

B. Kroposki, T. Basso, and R. DeBlasio

7. PERFORMING ORGANIZATION NAME(S) AND ADDRESS(ES)

National Renewable Energy Laboratory

1617 Cole Blvd.

Golden, CO 80401-3393

DP03.1001

9. SPONSORING/MONITORING AGENCY NAME(S) AND ADDRESS(ES)

8. PERFORMING ORGANIZATION

REPORT NUMBER

NREL/CP-560-35569

10. SPONSORING/MONITORING AGENCY REPORT NUMBER

11. SUPPLEMENTARY NOTES

12a. DISTRIBUTION/AVAILABILITY STATEMENT

National Technical Information Service

12b. DISTRIBUTION CODE

U.S. Department of Commerce

5285 Port Royal Road

Springfield, VA 22161

13. ABSTRACT (Maximum 200 words)

With the publication of IEEE $1547-2003^{\mathrm{TM}}$ Standard for Interconnecting Distributed Resources With Electric Power Systems, the electric power industry has a need to develop tests and procedures to verify that interconnection equipment meets 1547 technical requirements. A new standard, IEEE P1547.1 ${ }^{\mathrm{TM}}$, is being written to give detailed tests and procedures for confirming that equipment meets the interconnection requirements. The National Renewable Energy Laboratory has been validating test procedures being developed as part of IEEE P1547.1. As work progresses on the validation of those procedures, information and test reports are passed on to the working group of IEEE P1547.1 for future revisions.

14. SUBJECT TERMS

Standards; 1547; testing; distributed generation; distributed energy; distributed power;

DG; DER; DP; Distribution and Interconnection R\&D; National Renewable Energy Laboratory; NREL

17. SECURITY CLASSIFICATION OF REPORT Unclassified
18. SECURITY CLASSIFICATION OF THIS PAGE Unclassified
19. SECURITY CLASSIFICATION OF ABSTRACT Unclassified
15. NUMBER OF PAGES

16. PRICE CODE

20. LIMITATION OF ABSTRACT

UL 